Check for updates

Cite this: RSC Adv., 2019, 9, 29225

Received 7th May 2019

Accepted 6th September 2019

DOI: $10.1039 / c 9 r a 03414 e$

rsc.li/rsc-advances

\section{Evaluation of plasmid DNA stability against ultrasonic shear stress and its in vitro delivery efficiency using ionic liquid $\left[\mathrm{Bmim}^{-}\left[\mathrm{PF}_{6}\right] \dagger\right.$}

\author{
Satya Ranjan Sarker, ${ }^{\text {ab }}$ Andrew S. Ball, ${ }^{c}$ Suresh K. Bhargava (D) *a \\ and Sarvesh K. Soni iD *ac
}

\begin{abstract}
The hydrophobic ionic liquid (IL) 1-butyl-3-methylimidazolium hexafluorophosphate [Bmim] $\left[\mathrm{PF}_{6}\right]$ forms nanostructures with negatively charged plasmid DNA through electrostatic interactions. The formation of plasmid DNA/IL nanostructures was confirmed by measuring the zeta potential of plasmid DNA as well as plasmid DNA/IL nanostructures. The zeta potential of the nanostructures was positive, although plasmid DNA is negatively charged. The positive zeta potential is due to the complexation between plasmid DNA and positively charged ionic liquid $\left[\mathrm{Bmim}_{[}\left[\mathrm{PF}_{6}\right]\right.$. The ability of ionic liquid $\left.[\mathrm{Bmim}] \mathrm{PF}_{6}\right]$ to protect plasmid DNA against ultrasonic shear stress was also investigated using an agarose gel electrophoretic assay and showed that ionic liquid stabilizes plasmid DNA against ultrasonication. The plasmid DNA and plasmid DNA/IL nanostructures were subjected to ultrasonic shear stress for different time periods and the biological functionality of pristine plasmid DNA (i.e., expression of the eGFP gene) as well as the self-assembled nanostructures was investigated in vitro using three different cell lines, COS7, HEK293 and HeLa. Ionic liquid [Bmim] [PF6] protected the plasmid DNA against ultrasonic shear stress and also enhanced gene transfection efficiency in vitro. Furthermore, the cytotoxicity of ionic liquid $\left[\mathrm{Bmim}_{[}\left[\mathrm{PF}_{6}\right]\right.$ was assayed in vitro using all three cell lines and the toxicity was very low. Therefore, the ionic liquid $\left[\mathrm{Bmim}_{[}\left[\mathrm{PF}_{6}\right]\right.$ stabilizes plasmid DNA against ultrasonic shear stress and also enhances its in vitro delivery efficiency.
\end{abstract}

\section{Introduction}

Non-viral vectors are being extensively studied for their potential use in gene therapy to treat various complicated diseases. Non-viral vectors protect plasmid DNA against physical, chemical, and enzymatic degradation and deliver the DNA molecule to the target site. For example, cationic liposomes,,$^{1-3}$ chitosan $^{4,5}$ and other positively charged nanoparticles ${ }^{6,7}$ form complexes with plasmid DNA through electrostatic interactions. However, the readily formed cationic liposomes/plasmid DNA complexes are relatively large (i.e., 300-400 nm) and heterogeneous in nature making them difficult to use in pharmaceutical applications. ${ }^{\mathbf{8 9}}$ The large and heterogeneous plasmid DNA/liposomes, ${ }^{\mathbf{3}}$ plasmid DNA/aerosols, ${ }^{\mathbf{1 0}}$ and plasmid DNA/peptides ${ }^{11}$ complexes can be reduced to smaller, and homogeneous particles using ultrasonication. Moreover, the

${ }^{a}$ Centre for Advanced Materials and Industrial Chemistry, RMIT University, Melbourne, Australia. E-mail: sarvesh.soni@rmit.edu.au; suresh.bhargava@rmit. edu.au

${ }^{b}$ Department of Biotechnology and Genetic Engineering, Jahangirnagar University, Savar, Dhaka 1342, Bangladesh

${ }^{c}$ School of Science, RMIT University, GPO Box 2476, Melbourne, VIC 3001, Australia † Electronic supplementary information (ESI) available. See DOI: 10.1039/c9ra03414e uncomplexed plasmid DNA gets degraded when exposed to high frequency ultrasonication, which is frequently used to reduce the hydrodynamic size of plasmid DNA/nonviral vector complexes. ${ }^{\mathbf{8 , 1 1}}$ Because of the ultrasonic cavitation, the structure of plasmid DNA can be interrupted in many ways such as breakage of single strands, double strands, rupture of hydrogen bonds, base destruction, as well as cross linking. ${ }^{12}$ These breaks occur due to the exposure of DNA directly to the physical forces or the synthesis of highly toxic sonochemicals such as hydrogen peroxide ${ }^{12,13}$ during the sonication process. Ultrasonic shear stress also modifies the coiling structure of plasmid DNA and converts the supercoiled plasmid to open circular, linear, or even fragments them..$^{10}$ Although ultrasonic shear stress degrades the plasmid DNA, many research groups have used high speed sonicative force to enhance the cellular uptake of DNA ${ }^{\mathbf{1 1}}$ and to improve the encapsulation efficiency of DNA into liposomes. ${ }^{11,14}$

Various polymers, ${ }^{15}$ peptides, ${ }^{\mathbf{1 1}}$ and lipids ${ }^{8}$ protect the plasmid DNA against high frequency ultrasonication, and endonucleases have been reported. However, these polymers are often toxic, expensive, difficult to synthesize, and bring about immunogenicity. ${ }^{\mathbf{1 , 2}}$

Ionic liquids (ILs) have been used as a green solvent to facilitate the polymerase chain reactions of $\mathrm{DNA}^{\mathbf{1 6}}$ and to extract double stranded (dsDNA) without using any other 
materials. ${ }^{17}$ They have also been used as a reaction solvent for water-insoluble macromolecules such as chitosan, cellulose, keratin, and silk fibroin. ${ }^{15,18}$ Furthermore, ionic liquids have been reported to enhance transcutaneous vaccination using proteins and peptide antigens ${ }^{19}$ and also help to preserve plasmid DNA for long-term storage at room temperature. ${ }^{20}$ The negatively charged plasmid DNA forms functional nanostructures with the positively charged hydrophobic ionic liquid [Bmim] $]$ PF6] through electrostatic interactions. ${ }^{21,22}$ ILs also interact with the hydrophobic bases of DNA through hydrophobic interactions ${ }^{23-25}$ and compact the coiling structure of DNA resulting in the reduced hydrodynamic diameter of the DNA/IL nanostructures. ${ }^{24}$ Recently, we have reported ${ }^{21}$ the application of hydrophobic ionic liquid as a non-viral plasmid DNA delivery vehicle to bacteria.

The plasmid delivery efficiency of non-viral vectors depends on their size, surface charge/zeta potential, biodegradability and biocompatibility, cargo loading ability and so on. To reduce the size of the non-viral vector/plasmid DNA complexes and maintain their size homogeneity, the complexes are subjected to sonication. The supercoiled structure of plasmid DNA shows the highest gene expression efficiency followed by circular DNA, with linear DNA showing the lowest gene expression efficiency. ${ }^{11}$

In this study, we focused on the potential application of hydrophobic ionic liquid $[\mathrm{Bmim}]\left[\mathrm{PF}_{6}\right]$ to stabilize plasmid DNA against high frequency water bath ultrasonication. In vitro gene expression into various cell lines was also performed to confirm that DNA in the plasmid DNA/IL nanostructures subjected to ultrasonic shear stress was still biologically functional. At the same time, the potential role of IL in in vitro plasmid DNA delivery to various cell lines such as COS-7, HeLa and HEK293 was investigated. The cytotoxicity of ionic liquid $[\mathrm{Bmim}]\left[\mathrm{PF}_{6}\right]$ was also investigated in all three cell lines.

\section{Materials and methods}

\section{Materials}

Ionic liquid (IL) 1-butyl-3-methylimidazolium hexafluorophosphate $\left([\mathrm{Bmim}]\left[\mathrm{PF}_{6}\right]\right)$ was purchased from Ionic Liquid Technologies (IoLiTec). Cervical Cancer Cells (HeLa cells), African Green Monkey Kidney Cells (COS7 cells), Human Embryonic Kidney Cells (HEK293 cells) were provided by the Micro Nano Research Facility (MNRF) at RMIT University. Dulbecco's Modified Eagles Medium (DMEM), fetal bovine serum (FBS), phosphate buffer saline (PBS) and penicillinstreptomycin were also obtained from the MNRF at RMIT University. 3-(4,5-Dimethylthiazol-2-yl)-2,5-diphenyltetrazolium bromide dye (MTT); pEGFP was obtained from the School of Science, RMIT University. Lipofectamine was purchased from Thermo Fisher Scientific, Australia.

\section{Preparation of plasmid DNA/ionic liquid (IL) complexes}

Plasmid DNA, with a reporter 'enhanced green fluorescent protein (pEGFP)' tag formed nanostructures with ionic liquid $[\mathrm{Bmim}]\left[\mathrm{PF}_{6}\right]$ through electrostatic interactions and the nanostructures were prepared according to the previously established protocol. ${ }^{21}$ The detailed protocol for the preparation of plasmid DNA/IL nanostructures has been described in the ESI Section. $\dagger$

\section{Investigation of the stability of plasmid DNA, and plasmid DNA/IL nanostructures against ultrasonic shear stress}

Plasmid DNA (200 ng) was subjected to high speed ultrasonic shear stress for different time periods $(10,20,30$, and $40 \mathrm{~min})$ using water bath ultrasonicator. Similarly, pDNA/IL nanostructures were also subjected to high speed ultrasonic shear stress for different time periods $(10,20,30,40,60,90$, and 120 min) by ultrasonication. The stability and functionality of plasmid DNA was investigated using agarose gel electrophoresis, and an in vitro GFP expression assay.

\section{Agarose gel electrophoresis}

Agarose gel electrophoresis was performed to investigate the stability of plasmid DNA and plasmid DNA/IL nanostructures against ultrasonic shear stress. Plasmid DNA and plasmid DNA/ IL nanostructures (after being subjected to ultrasonic shear stress for different time periods) were mixed with bromophenol blue and same amount of DNA (100 ng) was loaded onto the wells of $1 \%$ agarose gel containing SYBR safe dye. A DNA ladder was also loaded onto two different wells of both sides of the gel. The gel was then run for 30 min using Tris-EDTA buffer at $90 \mathrm{~V}$ ensuring that the dye migrated at least two-thirds of the gel. The subsequent gel was documented using a Bio-Rad Gel-doc system.

\section{Determination of the zeta potential}

The zeta potential of both plasmid DNA and plasmid DNA/IL nanostructures was determined using a Zetasizer (Malvern, Nano Range, UK).

\section{Cell cultures}

COS7 cells (African Green Monkey Kidney Cells), HeLa cells (Cervical Cancer Cells), and HEK293 (Human Embryonic Kidney Cells 293) were obtained from the PC2 mammalian cell laboratory's cell repository, MicroNano Research facility at RMIT University and cultured in DMEM supplemented with heat inactivated $10 \% \mathrm{FBS}, 100 \mathrm{IU} \mathrm{mL} \mathrm{m}^{-1}$ penicillin, and $100 \mu \mathrm{g}$ $\mathrm{mL}^{-1}$ penicillin/streptomycin. All cell cultures were maintained in an atmosphere of $5 \% \mathrm{CO}_{2}$ at $37{ }^{\circ} \mathrm{C}$.

\section{In vitro gene expression assay}

COS7, HEK293, and HeLa cells were used to evaluate the stability, biological functionality as well as the gene delivery efficiency of pDNA/IL nanostructures. COS7 cells $\left(1 \times 10^{5}\right.$ cells per well), HEK293 cells $\left(1 \times 10^{5}\right.$ cells per well), and HeLa cells $(1$ $\times 10^{5}$ cells per well) were seeded into 24 well plates and cultured with DMEM containing $10 \%$ FBS and 1\% penicillin/ streptomycin and incubated in an atmosphere of $5 \% \mathrm{CO}_{2}$ and $37{ }^{\circ} \mathrm{C}$ until the cells reached $\sim 80 \%$ confluency. The medium in each well of the cell culture plates was then exchanged with pDNA/lipofectamine nanostructures sonicated for different 
time points $(10,20,30$ and $40 \mathrm{~min})$ in the presence of $10 \% \mathrm{FBS}$ and incubated for $24 \mathrm{~h}$ at $37{ }^{\circ} \mathrm{C}$ and $5 \% \mathrm{CO}_{2}$. Furthermore, pDNA/IL nanostructures, sonicated for different time points $(10,20,30,40,60,90$ and $120 \mathrm{~min})$ were mixed with either $1 \mu \mathrm{L}$ or $2 \mu \mathrm{L}$ lipofectamine (LA) and incubated for $20 \mathrm{~min}$ at room temperature to allow the formation of pDNA/IL/LA nanostructures. An aliquot $(1 \mu \mathrm{L})$ of $\mathrm{pDNA} / \mathrm{IL} / \mathrm{LA}$ nanostructures, prepared with LA were incubated with HeLa cells and the nanostructures prepared with LA $(2 \mu \mathrm{L})$ were incubated with the COS7 and HEK293 cells. All the cells lines were incubated for $24 \mathrm{~h}$ in the presence of $10 \% \mathrm{FBS}$ in a $5 \% \mathrm{CO}_{2}$ incubator at $37^{\circ} \mathrm{C}$. The medium was then replaced with fresh complete DMEM containing $10 \%$ FBS and incubated for another $24 \mathrm{~h}$ under the same condition. Finally, the green fluorescent protein (GFP) positive cells were observed using a fluorescent microscope (ZOE, Biorad) and GFP positive cells were counted.

\section{MTT assay}

Cytotoxicity was evaluated using the 3-(4,5-dimethylthiazol-2yl)-2,5-diphenyltetrazolium bromide (MTT) assay method. ${ }^{26}$ Before the cell viability assay, COS7, HeLa and, HEK293 cells were seeded in a 96-well plate at a density of $5 \times 10^{3}$ cells per well and incubated overnight in a $5 \% \mathrm{CO}_{2}$ incubator at $37^{\circ} \mathrm{C}$. After incubation $\left(1 \times 10^{5}\right.$ cells per well $)$, the old media was replaced with $100 \mu \mathrm{L}$ complete DMEM (DMEM containing 10\% FBS, and $1 \%$ penicillin/streptomycin) containing different volumes of ionic liquid $(0.015 \mu \mathrm{L}$ to $4.43 \mu \mathrm{g}, 0.03 \mu \mathrm{L}$ to $8.87 \mu \mathrm{g}$, $0.06 \mu \mathrm{L}$ to $17.75 \mu \mathrm{g}, 0.125 \mu \mathrm{L}$ to $35.5 \mu \mathrm{g}, 0.25 \mu \mathrm{L}$ to $71 \mu \mathrm{g}$, and 0.5 $\mu \mathrm{L}$ to $142 \mu \mathrm{g}$ ) and incubated for $24 \mathrm{~h}$ in a $5 \% \mathrm{CO}_{2}$ incubator at $37^{\circ} \mathrm{C}$. After $24 \mathrm{~h}$, the medium containing different volumes of ionic liquid was aspirated and $100 \mu \mathrm{L}$ of culture media (i.e., DMEM) containing $5 \mathrm{mg} \mathrm{mL}^{-1}$ MTT (thiazolyl blue tetrazolium bromide) was added to each well and cells were further incubated for $4 \mathrm{~h}$ in dark at $37^{\circ} \mathrm{C}$. After $4 \mathrm{~h}$ incubation, the media containing MTT was removed and DMSO $(100 \mu \mathrm{L})$ was added to each well to solubilize the crystallized formazan product. The plates were read on a micro-plate reader at $570 \mathrm{~nm}$ and a reference wavelength of $630 \mathrm{~nm}$.

The wells treated with only DMEM medium were used as control. Cell viability was calculated as follows: cell viability $=$ $\mathrm{OD}_{570}($ sample $) / \mathrm{OD}_{570}$ (control) $\times 100 \%$. All the experiments were carried out in triplicate to ensure the reproducibility.

\section{Results and discussion}

\section{Analysis of DNA stability through electrophoretic assay}

The ability of the hydrophobic ionic liquid $[\mathrm{Bmim}]\left[\mathrm{PF}_{6}\right]$ to protect plasmid DNA against high frequency ultrasonic shear stress was investigated through agarose gel electrophoresis assay. Fig. 1 shows the presence of two distinct bands (i.e., one at the bottom and the other one at the middle) and a smear band in the gel. The intensity of the bands for DNA/IL nanostructures was greater at all time points of sonication when compared to that of the native DNA. Furthermore, the ultrasonic shear stress converts supercoiled plasmid to open circular, linear or even fragmented DNA. ${ }^{10}$ The positively charged hydrophobic IL forms electrostatic interactions with the negatively charged plasmid $\mathrm{DNA}^{21}$ protecting the plasmid DNA against high frequency ultrasonic shear stress.

Furthermore, Fig. 1 also showed that the smear bands of the IL treated samples migrate consistently farther through the gel than those of the non-IL treated samples. The fact that the unsonicated IL-treated sample (0 hour) showed the same smear band shift as the sonicated samples (10-90 min) suggested that this increase in fragment migration was not due to sonication. In our previous report, ${ }^{21}$ for the CD spectra of DNA-IL, we observed an intense long wave positive band for DNA-IL that restrict various degree of freedom of DNA fragments and it led for farther and faster migration of DNA-IL fragments in agarose gel.

\section{Determination of the zeta potential of plasmid DNA and plasmid DNA/IL nanostructures}

The zeta potentials of native plasmid DNA and plasmid DNA/IL nanostructures were $-0.259 \pm 0.03 \mathrm{mV}$, and $0.360 \pm 0.04 \mathrm{mV}$, respectively (Table S1†). Zeta potential of the nanostructures plays important role in their stability as well as their cellular uptake efficiency. ${ }^{27}$ As the zeta potential increases in both the positive and negative scale, the stability of the nanostructures increases. Usually, particles with positive zeta potential interact more with the negatively charged cell membrane and their cellular uptake efficiency is also very high. ${ }^{28}$

\section{Analysis of the biological functionality of the pDNA/IL nanostructures}

The biological functionality of pristine plasmid DNA and plasmid DNA/IL nanostructures were investigated using three different cell lines, COS7, HEK293 and HeLa cells in terms of their transfection efficiency. All transfection assays were performed in the presence of $10 \%$ fetal bovine serum (FBS). When native plasmid DNA was incubated with COS7 cells, there was no fluorescent positive cells (Fig. 2a) observed due to electrostatic repulsion among the negatively charged pDNA and COS7 cells. In contrast, when pDNA (200 ng) was subjected to ultrasonic shear stress for $0,10,20,30$ and $40 \mathrm{~min}$, and thereafter complexed with lipofectamine, no fluorescent positive COS7 cells was observed for pDNA subjected to ultrasonication for 30 , and $40 \mathrm{~min}$ (Fig. 2e and f). This is likely due to extensive fragmentation of DNA ${ }^{11}$ through rupturing of the DNA double helical structure, damage to the phosphodiester bonds as well as the ribose sugars due to the high speed ultrasonic shear stress. ${ }^{8}$ The number of fluorescent positive COS7 cells were similar when pDNA was subjected to ultrasonication for 0,10 , and $20 \mathrm{~min}$ (Fig. $2 \mathrm{~b}-\mathrm{d}$ and S1†). These results confirm that the structure and functionality of the plasmid DNA is retained for up to 20 minutes of ultrasonication.

When plasmid DNA was complexed with hydrophobic ionic liquid $\left[\mathrm{Bmim}^{-}\left[\mathrm{PF}_{6}\right]\right.$ to make pDNA/IL nanostructures and incubated with African green monkey kidney cells (i.e., COS7 cells), there was no fluorescent positive cells (Fig. 3a). This may be due to the almost neutral zeta potential of the nanostructures (Table S1†) which results in their aggregation and therefore no cellular 


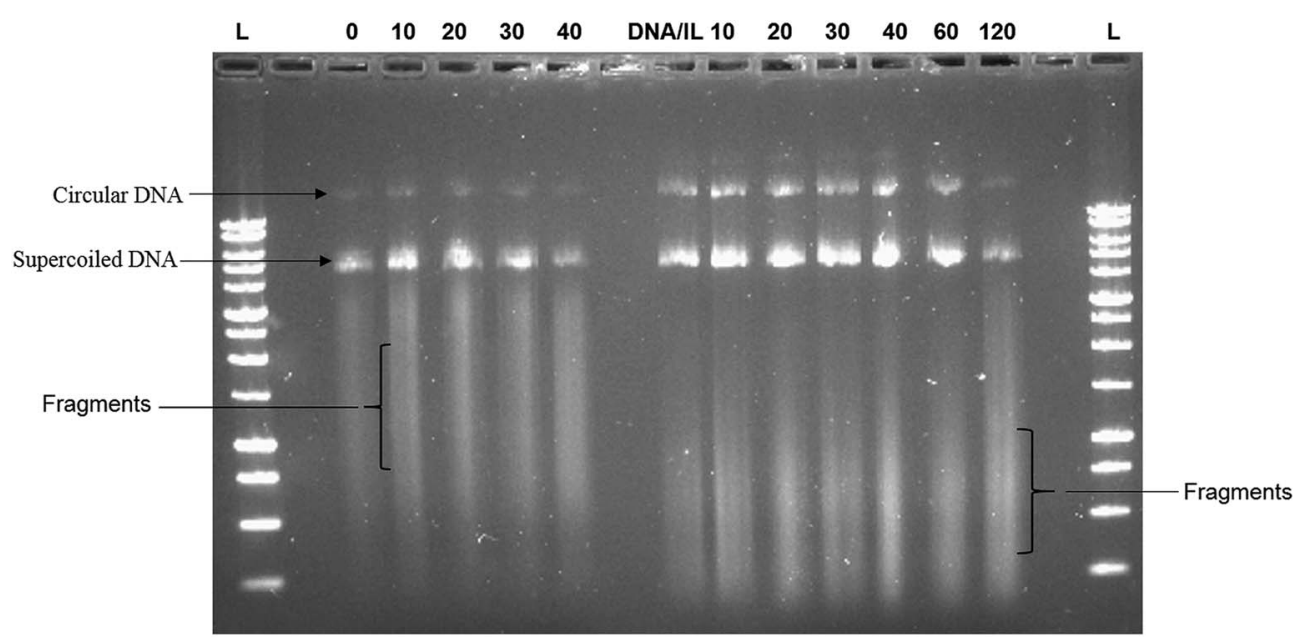

Fig. 1 The stability of plasmid DNA, and plasmid DNA/IL nanocomplexes against ultrasonic shear stress was investigated using agarose gel electrophoresis assay. Both the plasmid DNA and plasmid DNA/IL nanocomplexes were subjected to ultrasonic shear stress for different time points. The plasmid DNA was exposed to ultrasonic shear stress for 0, 10, 20, 30, and 40 minutes. However, the plasmid DNA/IL nanocomplexes were exposed to ultrasonic shear stress for $0,10,20,30,40,60,90$, and 120 minutes.

uptake. However, when the pDNA/IL nanostructures were subjected to ultrasonic shear stress for $0,10,20,30,40,60,90$, and $120 \mathrm{~min}$ and complexed with the commercially available cationic gene delivery agent lipofectamine, the percent of fluorescent positive cells were $80 \%, 98 \%, 97 \%, 85 \%, 78 \%, 65 \%$, $65 \%$, and $50 \%$, respectively (Fig. $3 \mathrm{~b}-\mathrm{i}$, and $\mathrm{S} 2 \dagger$ ). The percentage of fluorescent positive cells increased when the nanostructures were subjected to ultrasonic shear stress for 10 , and $20 \mathrm{~min}$, and thereafter decreased. The observed increased transfection efficiency may be due to the ultrasonic shear stress that reduces the nanostructures size and increases the stability against serum endonuclease. ${ }^{\mathbf{1 1 2 9}}$ When the small sized pDNA/IL nanostructures interact with the positively charged lipofectamine, they form positively charged stable pDNA/IL/LA complexes that are readily taken up by the cells and bring about higher transfection efficiency. The size of the particles play an important role in the cellular uptake efficiency. ${ }^{27}$ The larger the particles size, the lower the cellular uptake efficiency and vice versa. The percentage of fluorescent positive cells reduced as the time of exposure of the pDNA/IL nanostructures to ultrasonic shear stress increased from $40 \mathrm{~min}$ to $120 \mathrm{~min}$ (Fig. $3 \mathrm{e}-\mathrm{i}$, and $\mathrm{S} 2 \dagger$ ). This reduction of the fluorescent positive cells is due to the extensive fragmentation and disruption of the DNA structure. ${ }^{11}$ (a)

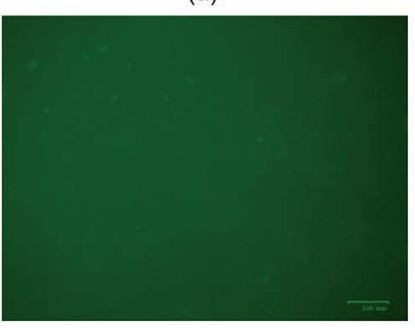

(b)

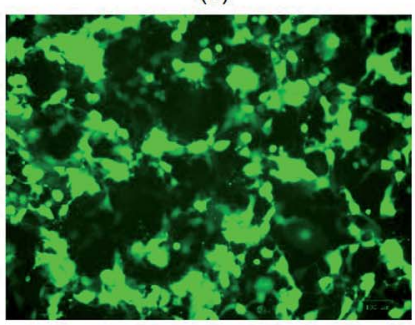

(e) (c)

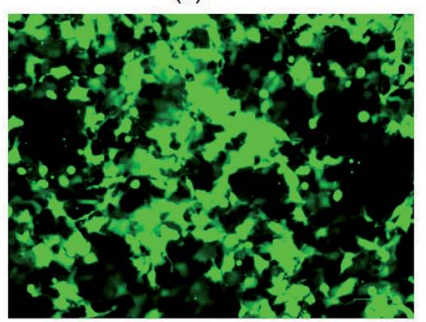

(d)

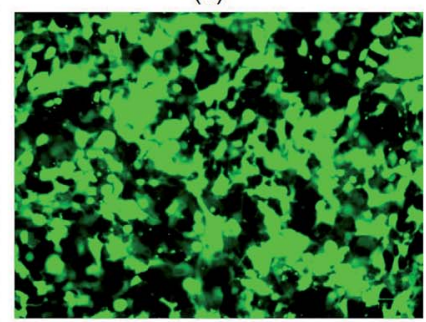

(f)
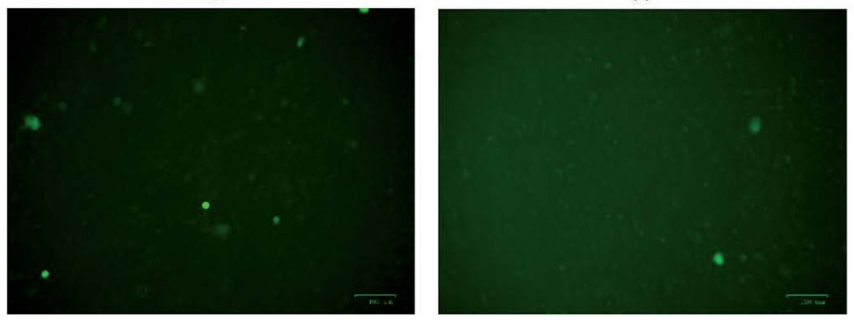

Fig. 2 Delivery of native plasmid DNA ( $p D N A$ ), and pDNA exposed to ultrasonic shear stress for different time periods to COS7 cells. (a) pDNA; (b) pDNA was complexed with lipofectamine (LA). (c) pDNA was subjected to 10 min ultrasonic shear stress and complexed with LA; (d) pDNA was subjected to 20 min ultrasonic shear stress and complexed with LA; (e) pDNA was subjected to 30 min ultrasonic shear stress and complexed with LA; (f) pDNA was subjected to 40 min ultrasonic shear stress and complexed with LA; scale bar: $100 \mu \mathrm{m}$. 
(a)

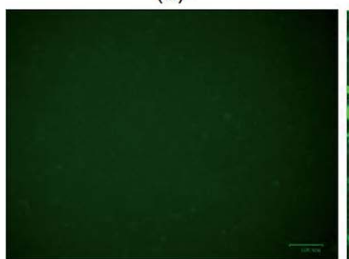

(f)

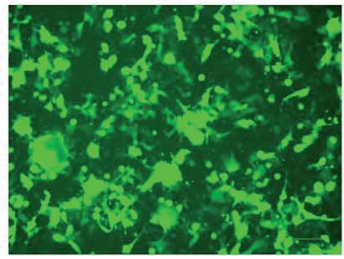

(b)

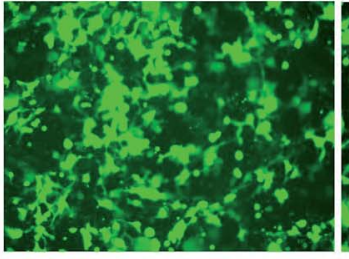

(g)

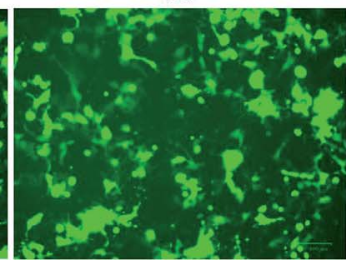

(c)

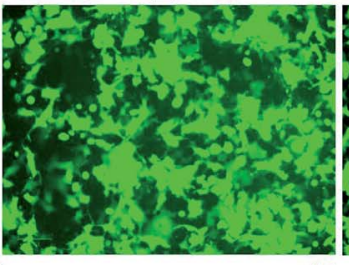

(h) (d)

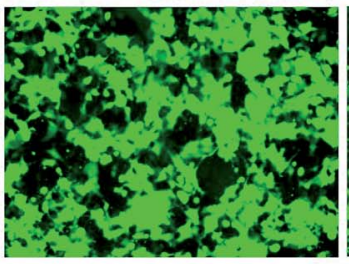

(e)

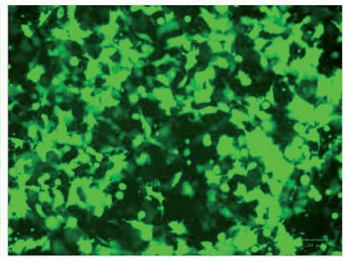

(i)

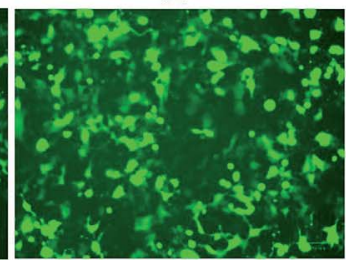

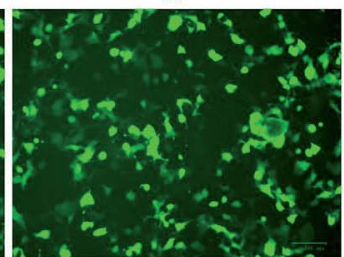

Fig. 3 Delivery of pDNA/IL nanocomplexes, and plasmid DNA/IL nanocomplexes subjected to ultrasonic shear stress for different time periods to COS7 cells. (a) pDNA/IL nanocomplexes; (b) pDNA/IL nanocomplexes were complexed with $2 \mu \mathrm{L}$ lipofectamine (LA). (c) pDNA/IL nanocomplexes were subjected to 10 min ultrasonic shear stress and complexed with LA; (d) pDNA/IL nanocomplexes were subjected to 20 min ultrasonic shear stress and complexed with LA; (e) pDNA/IL nanocomplexes were subjected to 30 min ultrasonic shear stress and complexed with LA; (f) pDNA/IL nanocomplexes were subjected to 40 min ultrasonic shear stress and complexed with LA; (g) pDNA/IL nanocomplexes were subjected to 60 min ultrasonic shear stress and complexed with LA; (h) pDNA/IL nanocomplexes were subjected to 90 min ultrasonic shear stress and complexed with LA; (i) pDNA/IL nanocomplexes were subjected to 120 min ultrasonic shear stress and complexed with LA; scale bar: 100 $\mu \mathrm{m}$.

Plasmid DNA/IL nanostructures were also delivered to human embryonic kidney 293 (HEK293) cells in the presence of $10 \%$ FBS. In HEK293 cells, plasmid DNA and pDNA/LA complexes were taken as negative control, and positive control, respectively. There were no fluorescent positive cells when only pDNA was incubated with HEK293 cells (Fig. 4a). However, the number of fluorescent positive cells in case of pDNA/IL/LA nanostructures transfected cells almost doubled compared to that of the pDNA/LA transfected cells (Fig. $4 \mathrm{~b}$ and $\mathrm{c}$, and $\mathrm{S} 3 \dagger)$. Hydrophobic ionic liquid $[\mathrm{Bmim}]\left[\mathrm{PF}_{6}\right]$ also enhances the transfection efficiency of pDNA/IL/LA nanostructures to cervical cancer cells, HeLa (Fig. S4 $\dagger$ ). In the presence of IL, the gene delivery efficiency of pDNA/LA to HEK293 cells, and HeLa cells increased almost 2-fold. This increase in the gene delivery efficiency in the presence of the ionic liquid [Bmim $]\left[\mathrm{PF}_{6}\right]$ is due to the protection of DNA against serum endonucleases and the hydrophobic interactions with the endosomal membranes. ${ }^{\mathbf{3 0 , 3 1}}$ This results in the rupture of endosomes and the release of plasmid DNA which then enter into the nucleus through the nuclear pore complex present on the membrane of the nucleus.

\section{Analysis of in vitro cytotoxicity of ionic liquids}

The cytotoxicity of the ionic liquid $[\mathrm{Bmim}]\left[\mathrm{PF}_{6}\right]$ was assayed in vitro in three different cell lines viz. COS7 cells, HEK293 cells, and HeLa cells. The ionic liquid is not toxic to all the cell lines in the presence of $[\mathrm{Bmim}]\left[\mathrm{PF}_{6}\right](0.015 \mu \mathrm{L})$. However, it shows toxicity to all the cell lines as the volume of IL increased from $0.03 \mu \mathrm{L}$ to $0.5 \mu \mathrm{L}$ (Fig. 5a-c). HEK 293 cells were more sensitive to IL, showing toxicity when the volume of IL was increased from $0.015 \mu \mathrm{L}$ to $0.03 \mu \mathrm{L}$. The degree of cytotoxicity varies for different cell lines due variation in their membrane molecular structure and composition ${ }^{32}$ which may bring about different degrees of interaction with the IL. The low cytotoxicity of the IL is due to the smaller alkyl chain length ${ }^{33}$ and ILs with C8 are more toxic when compared to those with $\mathrm{C} 6$ and $\mathrm{C} 4$, regardless (a)

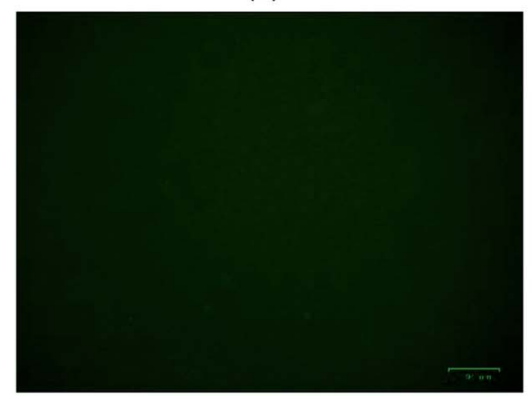

(b)

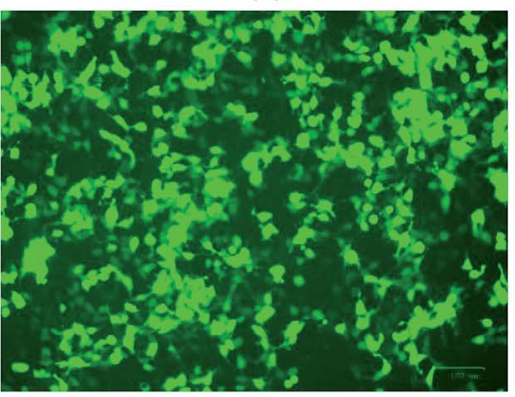

(c)

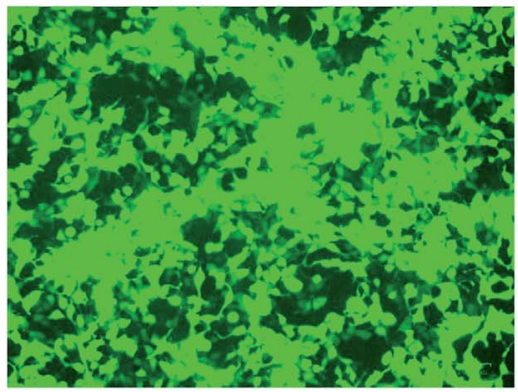

Fig. 4 Delivery of plasmid DNA (pDNA), and pDNA/IL nanocomplexes to HEK293 cells. (a) Only pDNA; (b) pDNA was complexed with lipofectamine (LA); (c) pDNA/IL nanocomplexes complexed with LA. Scale bar: $100 \mu \mathrm{m}$. 

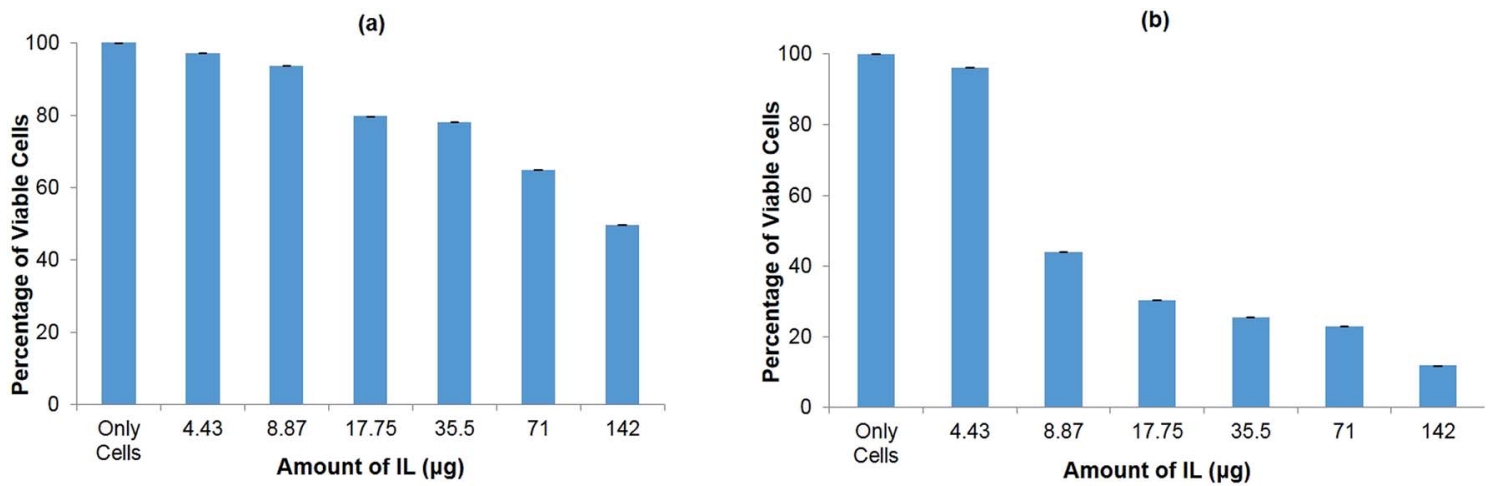

(c)

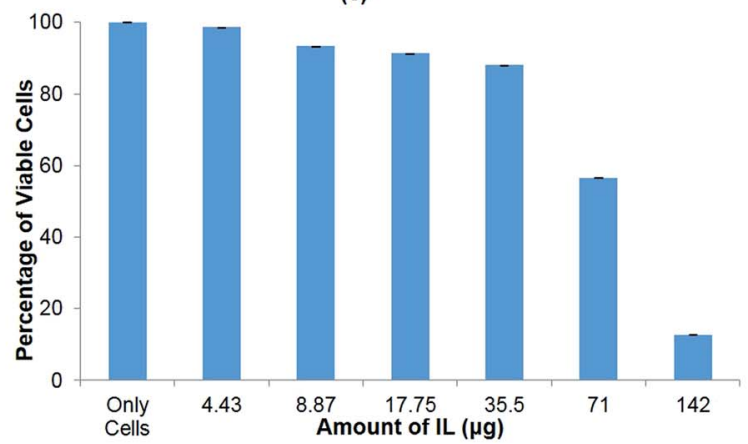

Fig. 5 In vitro cytotoxicity assay for hydrophobic ionic liquid (IL) [Bmim] [PF6] to different cell lines. (a) COS7 cells; (b) HEK293 cells; (c) HeLa cells.

of the type of cation they contain. ${ }^{34}$ It has been reported that the longer alkyl chain brings about cytotoxicity upon inhibiting the acetylcholinesterase enzyme. ${ }^{34}$ The elongated alkyl chain length also increases the lipophilicity of the ILs which is responsible for the incorporation of IL with the phospholipid bilayers of biological membranes through hydrophobic interactions. ${ }^{34}$ The toxicity of ILs can also be attributed to their membrane permeability altering the physical properties of the lipid bilayer. ${ }^{29,35,36}$ Furthermore, the structure of $\left[\mathrm{Bmim}^{-}\right]\left[\mathrm{PF}_{6}\right]$ contains a imidazolium ring which is similar to the structure of detergents, pesticides and antibiotics that disturbs the cell membrane lipid structure or cationic surfactants that cause membrane-bound protein disruption ${ }^{37}$ and cause the cell death.

\section{Conclusions}

The hydrophobic ionic liquid $[\mathrm{Bmim}]\left[\mathrm{PF}_{6}\right]$ protects plasmid DNA against high frequency ultrasonic shear stress for up to $120 \mathrm{~min}$. Plasmid DNA usually gets degraded after $30 \mathrm{~min}$ of ultrasonication. Thus, IL could be used as a potential agent to protect plasmid DNA against mechanical forces as well as various serum endonucleases. Ionic liquid also enhances DNA transfection efficiency to a variety of cell lines such as COS7 cells, HEK293 cells as well as HeLa cells in the presence of serum proteins. Therefore, ionic liquid $\left[\mathrm{Bmim}^{\mathrm{m}}\right]\left[\mathrm{PF}_{6}\right]$ stabilizes plasmid DNA against ultrasonic shear stress and enhances their in vitro delivery efficiency. Due to its low cytotoxicity and ability to increase the gene transfection efficiency, IL can be used as a co-delivery agent to deliver nucleic acids, oligonucleotides (e.g., siRNA, and shRNA), and other biological macromolecules such as antibodies.

\section{Conflicts of interest}

There is no conflict to declare.

\section{Acknowledgements}

The authors acknowledge Micro Nano Research Facility of RMIT University. S. R. S. thanks the Department of Education and Training, Govt. of Australia, for the award of an Endeavour Executive Fellowship.

\section{References}

1 S. R. Sarker, S. Arai, M. Murate, H. Takahashi, M. Takata, T. Kobayashi and S. Takeoka, Int. J. Pharm., 2012, 422, 364373.

2 S. R. Sarker, Y. Aoshima, R. Hokama, T. Inoue, K. Sou and S. Takeoka, Int. J. Nanomed., 2013, 8, 1361-1375.

3 Y. Aoshima, R. Hokama, K. Sou, S. R. Sarker, K. Iida, H. Nakamura, T. Inoue and S. Takeoka, ACS Chem. Neurosci., 2013, 4, 1514-1519.

4 B. Shi, Z. Shen, H. Zhang, J. Bi and S. Dai, Biomacromolecules, 2012, 13, 146-153.

5 J. Deng, Y. Zhou, B. Xu, K. Mai, Y. Deng and L. M. Zhang, Biomacromolecules, 2011, 12, 642-649.

6 J. J. Green, E. Chiu, E. S. Leshchiner, J. Shi, R. Langer and D. G. Anderson, Nano Lett., 2007, 7, 874-879. 
7 C. H. Jones, C. K. Chen, M. Jiang, L. Fang, C. Cheng and B. A. Pfeifer, Mol. Pharmaceutics, 2013, 10, 1138-1145.

8 E. K. Wasan, D. L. Reimer and M. B. Bally, J. Pharm. Sci., 1996, 85, 427-433.

9 H. Hofland and L. Huang, Biochem. Biophys. Res. Commun., 1995, 207, 492-496.

10 S. J. Eastman, J. D. Tousignant, M. J. Lukason, H. Murray, C. S. Siegel, P. Constantino, D. J. Harris, S. H. Cheng and R. K. Scheule, Hum. Gene Ther., 1997, 8, 313-322.

11 R. C. Adami, W. T. Collard, S. A. Gupta, K. Y. Kwok, J. Bonadio and K. G. Rice, J. Pharm. Sci., 1998, 87, 678-683.

12 T. Kondo, S. Arai, M. Kuwabara, G. Yoshii and E. Kano, Radiat. Res., 1985, 104, 284-292.

13 D. L. Miller, R. M. Thomas and M. E. Frazier, Ultrasound Med. Biol., 1991, 17, 729-735.

14 I. Leibiger, B. Leibiger, D. Sarrach, R. Walther and H. Zuhlke, Biomed. Biochim. Acta, 1990, 49, 1193-1200.

15 H. Chen, S. Cui, Y. Zhao, C. Zhang, S. Zhang and X. Peng, PLoS One, 2015, 10, e0121817.

16 Y. Shi, Y. L. Liu, P. Y. Lai, M. C. Tseng, M. J. Tseng, Y. Li and Y. H. Chu, Chem. Commun., 2012, 48, 5325-5327.

17 J. H. Wang, D. H. Cheng, X. W. Chen, Z. Du and Z. L. Fang, Anal. Chem., 2007, 79, 620-625.

18 R. P. Swatloski, S. K. Spear, J. D. Holbrey and R. D. Rogers, J. Am. Chem. Soc., 2002, 124, 4974-4975.

19 S. Araki, R. Wakabayashi, M. Moniruzzaman, N. Kamiya and M. Goto, Med. Chem. Commun., 2015, 6, 2124-2128.

20 R. Vijayaraghavan, A. Izgorodin, V. Ganesh, M. Surianarayanan and D. R. MacFarlane, Angew. Chem., 2010, 49, 1631-1633.

21 S. K. Soni, S. Sarkar, N. Mirzadeh, P. R. Selvakannan and S. K. Bhargava, Langmuir, 2015, 31, 4722-4732.

22 D. H. Cheng, X. W. Chen, J. H. Wang and Z. L. Fang, Chemistry, 2007, 13, 4833-4839.
23 I. Khimji, K. Doan, K. Bruggeman, P.-J. J. Huang, P. Vajha and J. Liu, Chem. Commun., 2013, 49, 4537.

24 S. Satpathi, A. Sengupta, V. M. Hridya, K. Gavvala, R. K. Koninti, B. Roy and P. Hazra, Sci. Rep., 2015, 5, 9137.

25 A. Chandran, D. Ghoshdastidar and S. Senapati, J. Am. Chem. Soc., 2012, 134, 20330-20339.

26 T. S. Reddy, H. Kulhari, V. G. Reddy, V. Bansal, A. Kamal and R. Shukla, Eur. J. Med. Chem., 2015, 101, 790-805.

27 H. K. Ha, J. W. Kim, M. R. Lee, W. Jun and W. J. Lee, AsianAustralas. J. Anim. Sci., 2015, 28, 420-427.

28 P. Yingchoncharoen, D. S. Kalinowski and D. R. Richardson, Pharmacol. Rev., 2016, 68, 701-787.

29 A. Vidiš, C. A. Ohlin, G. Laurenczy, E. Küsters, G. Sedelmeier and P. J. Dyson, Adv. Synth. Catal., 2005, 347, 266-274.

30 Y. Zhang, X. Chen, J. Lan, J. You and L. Chen, Chem. Biol. Drug Des., 2009, 74, 282-288.

31 R. R. Mazid, A. Cooper, Y. Zhang, R. Vijayaraghavan, D. R. MacFarlane, C. Cortez-Jugo and W. Cheng, RSC Adv., 2015, 5, 43839-43844.

32 K. Romoren, B. J. Thu, N. C. Bols and O. Evensen, Biochim. Biophys. Acta, 2004, 1663, 127-134.

33 X. Liu, C. Ji, Q. Yang, Z. Bao, X. Fan, Y. Yang and H. Xing, ACS Sustainable Chem. Eng., 2017, 5, 1974-1981.

34 X. Wang, C. A. Ohlin, Q. Lu, Z. Fei, J. Hu and P. J. Dyson, Green Chem., 2007, 9, 1191.

35 M. T. Garcia, N. Gathergood and P. J. Scammells, Green Chem., 2005, 7, 9.

36 B. Jastorff, K. Mölter, P. Behrend, U. Bottin-Weber, J. Filser, A. Heimers, B. Ondruschka, J. Ranke, M. Schaefer, H. Schröder, A. Stark, P. Stepnowski, F. Stock, R. Störmann, S. Stolte, U. Welz-Biermann, S. Ziegert and J. Thöming, Green Chem., 2005, 7, 362.

37 R. J. Bernot, E. E. Kennedy and G. A. Lamberti, Environ. Toxicol. Chem., 2005, 24, 1759. 